\title{
mRNA Decay Rates in Late-Developing Dictyostelium discoideum Cells Are Heterogeneous, and Cyclic AMP Does Not Act Directly To Stabilize Cell-Type-Specific mRNAs
}

\author{
RICHARD E. MANROW† AND ALLAN JACOBSON* \\ Department of Molecular Genetics and Microbiology, University of Massachusetts Medical School, \\ Worcester, Massachusetts 01655
}

Received 11 April 1988/Accepted 15 July 1988

\begin{abstract}
We reevaluated the use of ${ }^{32} \mathrm{PO}_{4}$ pulse-chases for analyzing $\mathrm{mRNA}$ decay rates in late-developing Dictyostelium cells. We found that completely effective $\mathrm{PO}_{4}$ chases could not be obtained in developing cells and that, as a consequence, the decay rates exhibited by some mRNAs were influenced by the rates at which they were transcribed. In developing cells disaggregated in the presence of cyclic AMP, the poly(A) ${ }^{+}$mRNA population turned over with an apparent half-life of $4 \mathrm{~h}$, individual $\mathrm{mRNA}$ decay rates were heterogeneous, and some prestalk and prespore mRNAs appeared to decay with biphasic kinetics. In cells disaggregated in the absence of cyclic AMP, all prestalk and prespore mRNAs decayed with biphasic kinetics. During the first 1 to $1.5 \mathrm{~h}$ after disaggregation in the absence of cyclic AMP, the cell-type-specific mRNAs were selectively degraded, decaying with half-lives of 20 to $30 \mathrm{~min}$; thereafter, the residual prestalk and prespore mRNA molecules decayed at rates that were similar to those measured in the presence of cyclic AMP. This short-term labilization of cell-type-specific mRNAs was observed even for those species not requiring cyclic AMP for their accumulation in developing cells. The observation that cell-type specific mRNAs can decay at similar rates in disaggregated cells with or without cyclic AMP indicates that this compound does not act directly to stabilize prestalk and prespore mRNAs during development and that its primary role in the maintenance of cyclic-AMP-dependent mRNAs is likely to be transcriptional.
\end{abstract}

In the presence of exogenous nutrients, the cells of the slime mold Dictyostelium discoideum multiply as individual amoebae (19). Under conditions of starvation, however, the amoebae form aggregates (containing $\sim 10^{5}$ cells each) which ultimately differentiate into fruiting bodies containing stalk cells and spores (19). This developmental program is characterized by changing patterns of gene expression (see references 7,18 , and 19 for reviews), and both transcriptional and posttranscriptional mechanisms have been implicated in regulating the observed changes $(6,11,15,26,27$, $31,32,34,35)$. One posttranscriptional mechanism employed by developing cells to regulate gene expression is the alteration of specific mRNA stability $(4,12)$. The analysis of mRNA stability during growth and development of $D$. discoideum has therefore received considerable attention $(5,8$, $21,22,25,29,33$ ).

The cytoplasmic poly $(\mathrm{A})^{+}$RNA in postaggregation $D$. discoideum cells can be divided into two major groups: (i) species that are transcribed at relatively high rates in growing cells and continue to be expressed in developing cells (i.e., constitutive mRNAs) and (ii) species that are found exclusively in developing cells or whose abundance is substantially increased during development (i.e., developmentally regulated mRNAs) $(3,8)$. The developmentally regulated $\mathrm{mRNAs}$ can be further divided into three classes on the basis of their respective cell-type localizations: i.e., prestalk mRNAs are found predominantly in prestalk cells, prespore mRNAs are found predominantly in prespore cells, and common mRNAs are found equally in both cell types $(1,27)$. Constitutive mRNAs represent, by sequence complexity and

\footnotetext{
* Corresponding author

† Present address: National Cancer Institute, Bethesda, MD 20892.
}

mass, approximately 65 to $70 \%$ of the cytoplasmic poly(A) ${ }^{+}$ RNA in late-developing cells $(3,8)$; the developmentally regulated species, comprised mostly of prestalk and prespore mRNAs, constitute the remainder $(1,3,8)$. Accumulation of most prestalk and prespore mRNAs in developing cells requires cyclic AMP (cAMP) $(6,16,26,27)$.

Three different methods have been employed to study mRNA stability during development of $D$. discoideum. Chung et al. (8) used the transcriptional inhibitors actinomycin $\mathrm{D}$ and daunomycin to block mRNA biosynthesis and then monitored the decay of preexisting molecules; Mangiarotti et al. $(21,22)$ measured mRNA decay rates by using both the approach to steady-state labeling method and ${ }^{32} \mathrm{PO}_{4}$ pulse-chase procedures. Based on their results, Chung et al. (8) and Mangiarotti et al. (21, 22; see also Chisolm et al. [7]) concluded that all mRNAs in late-developing cells turn over with 4-h half-lives and that these uniform decay kinetics can be observed both in normal developing cells (i.e., intact aggregates) and in cells disaggregated in the presence of cAMP. When cells were disaggregated in the absence of cAMP, most of the prestalk and prespore mRNAs appeared to be selectively degraded, decaying with half-lives of 20 to $30 \mathrm{~min}$; however, the decay rates of the common mRNAs and the constitutive mRNAs were unaffected by the absence of cAMP $(7,8,21,22)$. The latter observations led to the additional conclusion that cAMP not only acts to promote the transcription of cell-type-specific mRNAs but also acts to stabilize these cAMP-dependent mRNAs in normal developing cells $(7,8,22)$. The accuracy of these observations and the validity of the conclusions drawn from them, however, may be questioned for a number of reasons. First, previous work from this laboratory has established that actinomycin $\mathrm{D}$ and daunomycin, at the concentrations used by Chung et al. (8), will kill growing $D$. discoideum cells (5). Although 
developing cells may be less susceptible to the toxic effects of these drugs, appropriate controls were not reported (8). Second, developing $D$. discoideum cells are not suitable for use in approach to steady-state labeling experiments because a population of developing cells is not uniform (i.e., cells with different developmental fates are present). In addition, cellular mass is reduced by at least a factor of 2 during development (19), dramatic changes in the rates of accumulation of specific RNAs can occur over relatively short periods of time $(1,20,27,28)$, and cellular pools of some metabolites (e.g., $\mathrm{PO}_{4}$ ) are subject to large fluctuations (19). Third, pulse-chase experiments done in this laboratory to determine mRNA decay rates in growing cells have suggested that entirely effective chases cannot be obtained in $D$. discoideum cells labeled with ${ }^{32} \mathrm{PO}_{4}(33)$. Although relative mRNA decay rates could be determined in these ${ }^{32} \mathrm{PO}_{4}$ pulse-chase experiments, the half-lives measured for individual mRNAs appeared to be overestimated by a factor of 1.5 to 2 (33). In view of this last observation, the observation of Casey et al. (5) that most mRNAs in vegetatively growing amoebae turn over with half-lives of $50 \mathrm{~min}$, and the results of Chung et al. (8), Mangiarotti et al. $(21,22)$, and Chisolm et al. (7), it could be argued that cell-type-specific mRNAs have inherently short half-lives which are masked during ineffective phosphate chases in the presence of cAMP (i.e., highlevel transcription of the respective genes and continued ${ }^{32} \mathrm{PO}_{4}$ incorporation during an ineffective chase will artifactually decrease measured mRNA decay rates). If correct, this would suggest that cAMP does not act to stabilize cell-type-specific mRNAs in developing $D$. discoideum cells. As an approach to clarifying these issues, we have reevaluated the use of ${ }^{32} \mathrm{PO}_{4}$ pulse-chases for analyzing mRNA decay rates in late-developing cells and have reassessed the hypothetical role of cAMP in stabilizing cell-type-specific mRNAs. Our experiments indicate that in late-developing cells (i) completely effective $\mathrm{PO}_{4}$ chases cannot be obtained; (ii) mRNA decay rates are much more heterogeneous than previously thought; (iii) reliable information about the decay rates of individual mRNAs cannot be deduced from the decay kinetics of total mRNA; (iv) disaggregation in the absence of cAMP leads to a selective and transient degradation of cell-type-specific mRNAs, including those mRNAs not requiring CAMP for their maintenance in disaggregated cells; and (v) cAMP does not act directly to stabilize prespore and prestalk mRNAs.

\section{MATERIALS AND METHODS}

Recombinant plasmids. The plasmid-bearing sequence complementary to a constitutively expressed mRNA, CON29, is the same as that designated p29 by Shapiro et al. (33). The cDNA plasmids complementary to developmentally regulated mRNAs were originally isolated from a bank described by Mehdy et al. (27). The cDNA-containing plasmids $10 \mathrm{C} 3,2 \mathrm{H} 3,2 \mathrm{H} 6,14 \mathrm{E} 6$, and $16 \mathrm{G} 1$ were generously provided by R. A. Firtel. The plasmid 10C3, containing sequences complementary to a developmentally regulated mRNA found both in prestalk cells and prespore cells, was renamed COM10C3; the plasmids $2 \mathrm{H} 3$ and $14 \mathrm{E} 6$, containing sequences complementary to mRNAs enriched in prespore cells, were renamed PSP2H3 and PSP14E6, respectively; the plasmids $2 \mathrm{H} 6$ and $16 \mathrm{G} 1$, containing sequences complementary to mRNAs enriched in prestalk cells, were renamed PSK2H6 and PSK16G1, respectively. The cDNA plasmids 7E3, 12H5, 15E3, and 18G1 were a generous gift from D. Ratner. The plasmids $7 \mathrm{E} 3,12 \mathrm{H} 5$, and $15 \mathrm{E} 3$, containing sequences complementary to mRNAs enriched in prespore cells, were renamed PSP7E3, PSP12H5, and PSP15E3; the plasmid $18 \mathrm{G} 1$, containing sequences complementary to an mRNA enriched in prestalk cells, was renamed PSK18G1.

Cell culture and development. $D$. discoideum AX3 was grown axenically in MES-HL5 medium at $22^{\circ} \mathrm{C}$ as described by Palatnik et al. (30). The cells were prepared for development by pelleting them $(1,000 \times g, 2 \mathrm{~min})$, washing them once in $0.2 \% \mathrm{NaCl}$, and then washing them twice in LPS (1 $\mathrm{mM} \mathrm{CaCl}_{2}, 1.3 \mathrm{mM} \mathrm{KCl}, 4.2 \mathrm{mM} \mathrm{MgSO}_{4}, 22 \mathrm{mM} \mathrm{NaH}_{2} \mathrm{PO}_{4}$, and $11 \mathrm{mM} \mathrm{Na} \mathrm{HPO}_{4}$ ). After the second LPS wash, the cells were suspended in LPS to a final concentration of $1.5 \times 10^{8}$ cells per $\mathrm{ml}$ and then deposited on $4.25-\mathrm{cm}$ Whatman 50 filters $\left(\sim 10^{8}\right.$ cells per filter). Each Whatman 50 filter rested on top of a single Millipore AP10047S1 support pad, and both the filters and the support pads were saturated with LPS before the cells were deposited. The cells were allowed to develop at $22^{\circ} \mathrm{C}$ for $13 \mathrm{~h}$ before further treatment.

Pulse-chase procedures. All operations were performed at $22^{\circ} \mathrm{C}$. Cells were pulse-labeled during the 13th and 14th hours of development by lifting the cell-bearing Whatman filters from their support pads and placing each one on a $150-\mu$ l droplet of carrier-free ${ }^{32} \mathrm{PO}_{4}$ (New England Nuclear Corp.). Depending upon the experiment, the droplets contained either 5.63 or $11.25 \mathrm{mCi}$ of ${ }^{32} \mathrm{PO}_{4}$. Control experiments have shown that cell viability is not affected by exposure to these levels of radioactivity. At the end of the labeling period, the incorporated ${ }^{32} \mathrm{PO}_{4}$ was chased either in normal cells (i.e., aggregated cells) or in disaggregated cells. Chases in normal cells were initiated by blotting the cellbearing filters alternately on Whatman $3 \mathrm{~mm}$ filter papers that were either supersaturated with LPS or dry (five cycles). After the cell-bearing filters were blotted, they were placed on fresh LPS-saturated Millipore support pads (see above), and the support pads were changed every $15 \mathrm{~min}$ for the duration of the chase. Chases in disaggregated cells were initiated as described above for normal cells, but after the final blotting on $3 \mathrm{~mm}$ paper the cells were stripped from their filters and disaggregated by vortex mixing in LPS containing EDTA $(10 \mathrm{mM})(5 \mathrm{ml}$ per filter of developing cells). The filters were then discarded, and the cells were transferred to centrifuge bottles with gaskets and washed twice with large volumes of LPS-EDTA. After the second wash, the cells were suspended in LPS-EDTA at a final concentration of $5 \times$ $10^{6}$ cells per $\mathrm{ml}$ and agitated on a platform shaker $(250 \mathrm{rpm})$. When the chase in disaggregated cells was performed in the presence of cAMP, this compound was added to the LPSEDTA solution at a concentration of $100 \mu \mathrm{M}$.

RNA extraction and purification. In most experiments, the first sample (designated $t_{0}$ ) was isolated 60 min after removal of the label. If the chase was done in aggregated cells, a single filter of cells was harvested at each time point. In this case, the cells were dislodged from the filters by vortex mixing in $5 \mathrm{ml}$ of LPS-EDTA and then pelleted. The pelleted cells were lysed in $2.5 \mathrm{ml}$ of $2 \%$ Cemulsol NPT12-12\% sucrose-1\% diethylpyrocarbonate-10 mM $\mathrm{Mg}\left(\mathrm{C}_{2} \mathrm{H}_{3} \mathrm{O}_{2}\right)_{2}-10$ mM NaCl-50 mM HEPES ( $N$-2-hydroxyethylpiperazine- $N^{\prime}$ 2-ethanesulfonic acid)- $\mathrm{NaOH}$ (pH 7.5), and the lysate was centrifuged at $12,000 \times g$ for $10 \mathrm{~min}$ at $4^{\circ} \mathrm{C}$ to pellet the nuclei and mitochondria. The postmitochondrial supernatant was recovered, mixed with $2.5 \mathrm{ml}$ of $1 \%$ sodium dodecyl sulfate (SDS)-1\% diethylpyrocarbonate-100 mM HEPES-NaOH (pH 7.5) and extracted three times with phenol-chloroform (2:1). The extracted RNA was ethanol precipitated twice, suspended in $400 \mu \mathrm{l}$ of diethylpyrocarbonate-treated, autoclaved $\mathrm{H}_{2} \mathrm{O}$, and stored at $-70^{\circ} \mathrm{C}$. When the chase was done 
in disaggregated cells, $20 \mathrm{ml}$ of cells $\left(\sim 10^{8}\right.$ cells $)$ was harvested, and cytoplasmic RNA was isolated as described above. Poly $(\mathrm{A})^{+}$RNA was purified from total cytoplasmic RNA by batch adsorption to and elution from oligo(dT)cellulose. The RNA from each time point was heated to $65^{\circ} \mathrm{C}$ for $5 \mathrm{~min}$, mixed with an equal volume of warmed $2 \times$ oligo(dT)-cellulose-binding buffer ( $1 \mathrm{M} \mathrm{NaCl}, 2 \mathrm{mM}$ EDTA, $1 \%$ SDS, $20 \mathrm{mM}$ Tris hydrochloride [pH 7.5]), and then added to a microfuge tube $(1.5 \mathrm{ml})$ containing $20 \mathrm{mg}$ of oligo(dT)-cellulose (type 3; Collaborative Research) that had been preequilibrated in $1 \times$ oligo $(\mathrm{dT})$-cellulose binding buffer. The RNA and oligo-(dT)-cellulose were mixed at room temperature on a rotating mixer for 10 to $15 \mathrm{~min}$, and then the oligo(dT)-cellulose was pelleted by centrifugation. Nonbinding material was removed from the oligo(dT)-cellulose by washing the resin twice with $1 \times$ oligo(dT)-cellulose binding buffer $(800 \mu$ l per sample) and twice with oligo(dT)cellulose wash buffer $(100 \mathrm{mM} \mathrm{NaCl}, 1 \mathrm{mM}$ EDTA, $10 \mathrm{mM}$ Tris hydrochloride [pH 7.5]) $(900 \mu l$ per sample). The bound $\operatorname{poly}(\mathrm{A})^{+}$RNA was eluted from the oligo(dT)-cellulose by washing the resin twice with diethylpryocarbonate-treated, autoclaved water that had been prewarmed to $37^{\circ} \mathrm{C}(450 \mu \mathrm{l}$ in first wash, $400 \mu l$ recovered; $400 \mu$ in second wash, $400 \mu l$ recovered; the two eluents were combined). The poly $(\mathrm{A})^{+}$ RNA eluents were ethanol precipitated at $-20^{\circ} \mathrm{C}$ overnight in Beckman SW50.1 centrifuge tubes, and the precipitates were pelleted by centrifugation at $40,000 \mathrm{rpm}$ at $4^{\circ} \mathrm{C}$ for $2 \mathrm{~h}$. The RNA pellets were suspended in $400 \mu$ l of diethylpyrocarbonate-treated, autoclaved water, and the suspended RNA was stored at $-70^{\circ} \mathrm{C}$. RNA yields and concentrations were determined by measurements of $A_{260}$, and RNA radioactivity was determined by trichloroacetic acid precipitation and scintillation spectrometry. The specific activity of the poly $(\mathrm{A})^{+}$RNA in the $t_{0}$ samples ranged from $6.0 \times 10^{4}$ to 1.0 $\times 10^{5} \mathrm{cpm} / \mu \mathrm{g}$.

DNA dots and hybridizations. Hybridization of each of the poly $(\mathrm{A})^{+}$RNA fractions isolated from cells during the time course of a chase to excess amounts of cloned cDNA immobilized on filters, followed by measurement of the relative amounts of labeled material hybridized, allows the determination of individual mRNA decay rates (33). Therefore, sets of Zeta-Probe (Bio-Rad Laboratories) membranes containing all of the cDNAs described above and pBR322 (as a hybridization control) were prepared by applying the DNA (denatured in $0.4 \mathrm{M} \mathrm{NaOH}$ at $37^{\circ} \mathrm{C}$ for $15 \mathrm{~min}$ ) to the membranes by using a Schleicher $\&$ Schuell dot blot manifold. The membrane sets contained one membrane for each time point in an experiment, and each of the membranes in a set contained duplicate amounts of either 1.0,2.5, and $5.0 \mu \mathrm{g}$ or 2.5 and $5.0 \mu \mathrm{g}$ of each type of DNA. After the DNA was applied to the membranes, they were washed twice at room temperature with $2 \times$ SSPE (24), air dried, and then washed again with $0.1 \times$ SSPE- $0.5 \%$ SDS for $1 \mathrm{~h}$ at $65^{\circ} \mathrm{C}$. Both prehybridization and hybridization were done in $50 \%$ formamide $-4 \times$ SSPE-1\% SDS. Identical amounts (1.6 to $2.6 \mu \mathrm{g})$ of labeled poly $(\mathrm{A})^{+}$RNA isolated at each time point during a chase were hybridized individually to the members of a membrane set. The RNA was heated to $65^{\circ} \mathrm{C}$ for $5 \mathrm{~min}$ and then chilled quickly before adding it to the hybridization solution; the hybridizations were done at $45^{\circ} \mathrm{C}$ for $48 \mathrm{~h}$. After the hybridization, the membranes were washed first at room temperature (once in $2 \times \mathrm{SSPE}-0.1 \%$ SDS and once in $0.1 \times$ SSPE- $0.1 \%$ SDS, 15 min each) and then at $60^{\circ} \mathrm{C}$ (twice in $0.1 \times$ SSPE-0.1\% SDS, $30 \mathrm{~min}$ each). The washed membranes were placed between layers of plastic wrap and put under X-ray film with a Dupont Cronex intensifying screen; the films were exposed at $-70^{\circ} \mathrm{C}$ for up to 2 weeks. Exposed $\mathrm{X}$-ray films were quantitated by densitometry with a Helena Laboratories Quick Scan R+D densitometer. Since a saturated level of hybridization was observed for all amounts of DNA on the membranes for all of the mRNAs studied (data not shown), average densities were calculated from the scans of all available dots. No hybridization was observed to dots containing pBR322 DNA, so that no corrections had to be made for background hybridization. Decay curves were generated for each mRNA by constructing semilogarithmic plots of the percentage of hybridizing labeled material remaining as a function of time (33).

RNA dots and hybridizations. To quantitate the amounts of specific mRNAs present in developing cells at various times after the disruption of cell-cell contacts in the absence of cAMP, total cytoplasmic RNA was purified from cells at designated times after disaggregation, and a set of ZetaProbe membranes containing duplicate 3.0- $\mu \mathrm{g}$ dots of the RNA from each time point was prepared. The RNA was applied to the membranes after denaturation for $5 \mathrm{~min}$ at $65^{\circ} \mathrm{C}$ in $50 \%$ formamide-2.2 $\mathrm{M}$ formaldehyde-10 $\mathrm{mM}$ $\mathrm{NaC}_{2} \mathrm{H}_{3} \mathrm{O}_{2}-1 \mathrm{mM}$ EDTA-40 mM morpholinepropanesulfonic acid- $\mathrm{NaOH}$ (pH 7.0), and the dots were washed with $2 \times$ SSPE. After the dots were washed, the membranes were dried and then incubated, with shaking, in 0.1 $\times$ SSPE $-0.1 \%$ SDS for $1 \mathrm{~h}$ at $65^{\circ} \mathrm{C}$. The membranes were prepared for hybridization by preincubation at $42^{\circ} \mathrm{C}$ for at least $4 \mathrm{~h}$ in $50 \%$ formamide-4× SSPE-1\% SDS-0.5\% BLOTTO (13)-0.5 mg of salmon sperm DNA per ml. The RNA on each membrane was hybridized with a specific ${ }^{32} \mathrm{P}$-labeled probe synthesized in a random-priming reaction (9) by using the gel-purified insert from one of the recombinant cDNA clones described above as a template. The probes were purified after synthesis by phenol extraction and centrifugation through small columns of Sephadex G-50 (Pharmacia). Approximately $10^{6}$ $\mathrm{cpm}$ of labeled probe was used in each hybridization reaction. Hybridizations were done at $42^{\circ} \mathrm{C}$ for at least $20 \mathrm{~h}$ in $47 \%$ formamide-3 $\times$ SSPE-10\% dextran sulfate-1\% SDS$0.5 \%$ BLOTTO- $0.4 \mathrm{mg}$ of salmon sperm DNA per ml. After the hybridization, the membranes were washed first at room temperature (once in $2 \times \mathrm{SSPE}-0.1 \%$ SDS and once in $0.2 \times$ SSPE- $0.1 \%$ SDS, 15 min each) and then at $55^{\circ} \mathrm{C}$ (twice in $0.2 \times$ SSPE-0.1\% SDS, $15 \mathrm{~min}$ each). The washed filters were placed between layers of plastic wrap and then put under X-ray film with an intensifying screen at $-70^{\circ} \mathrm{C}$. The $\mathrm{X}$-ray films were exposed for up to $48 \mathrm{~h}$, and the relative extent of hybridization to each dot was measured by densitometry as described above for DNA dots.

Northern (RNA) blots and hybridizations. Total cytoplasmic RNA from growing, normal developing, and disaggregated developing cells was electrophoresed in $1.2 \%$ agarose gels containing 2.2 $\mathrm{M}$ formaldehyde (17) and blotted to Zeta-Probe membranes in $1 \times$ SSPE. The membranes were prepared for hybridization by incubation at $42^{\circ} \mathrm{C}$ in $50 \%$ formamide-5 $\times$ SSPE-Denhardt solution (24)-1\% SDS-250 $\mu \mathrm{g}$ of salmon sperm DNA per ml. The hybridization probes for specific mRNAs were prepared as described above for the RNA dots. Hybridization reactions were done at $42^{\circ} \mathrm{C}$ in $47 \%$ formamide-5 $\times$ SSPE-1 $\times$ Denhardt solution-10\% dextran sulfate $-0.5 \%$ SDS-200 $\mu \mathrm{g}$ of salmon sperm DNA per ml. After the hybridization, the membranes were washed first in $2 \times$ SSPE-1\% SDS and then in $2 \times$ SSPE- $0.1 \%$ SDS (15 min each). Then the membranes were washed at $50^{\circ} \mathrm{C}$ in $0.2 \times$ SSPE-0.1\% SDS (two washes, $15 \mathrm{~min}$ each). The washed membranes were placed between layers of plastic wrap and 

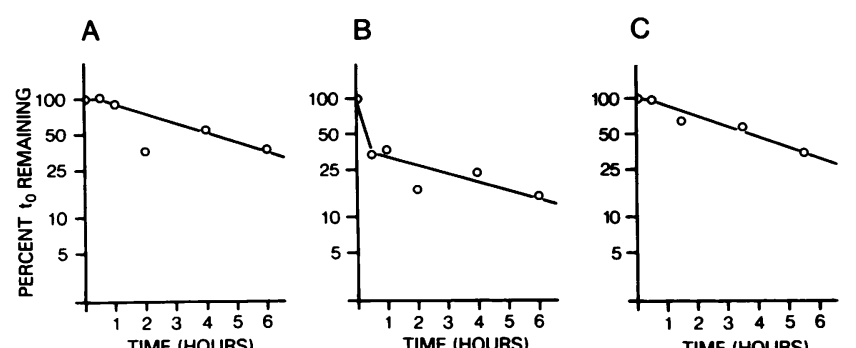

FIG. 1. Decay of ${ }^{32} \mathrm{PO}_{4}$-labeled poly(A) ${ }^{+}$RNA in developing Dictyostelium cells. $D$. discoideum cells were pulse-labeled with ${ }^{32} \mathrm{PO}_{4}$ during the 13th and 14th hours of development, and the incorporated label was chased either in aggregated cells (i.e., normal developing cells) or in cells disaggregated in the presence or absence of cAMP. At designated times during the chase, samples of the cells were harvested, and total cytoplasmic RNA was purified. Poly $(\mathrm{A})^{+}$ RNA was purified from the total cytoplasmic RNA by batch adsorption to and elution from oligo(dT)-cellulose. RNA yields and concentrations were measured by determining the $A_{260}$, and RNA radioactivity was measured by trichloroacetic acid precipitation and scintillation spectrometry. Source of RNA: (A) cells disaggregated in the presence of cAMP $(100 \mu \mathrm{M})$; (B) cells disaggregated in the absence of cAMP; (C) aggregated cells.

then put under X-ray film with an intensifying screen at $-70^{\circ} \mathrm{C}$.

\section{RESULTS}

We used two approaches to measure mRNA decay rates in developing cells. In the first approach we used a pulse-chase procedure to monitor the decay of both total cytoplasmic poly $(\mathrm{A})^{+}$RNA and 10 individual mRNAs. This procedure was applied to normal developing cells (intact aggregates) and to cells disaggregated in the presence or absence of cAMP. In the second approach, we monitored the relative levels of individual mRNAs under conditions where their synthesis had been markedly reduced, i.e., in cells disaggregated in the absence of cAMP. The results of our experiments are described below.

Pulse-chase analysis of mRNA decay in cells disaggregated in the presence or absence of cAMP. Cells developing on filter pads were pulse-labeled with ${ }^{32} \mathrm{PO}_{4}$ during the 13th and 14th hours of development; then the cells were disaggregated, washed extensively, and maintained as individual cells (for up to $6.5 \mathrm{~h}$ ) in a chase buffer containing unlabeled $\mathrm{PO}_{4}$ with or without CAMP (see Materials and Methods). In all experiments except those with disaggregated cells without cAMP, the first samples were isolated $60 \mathrm{~min}$ after removal of the label. In experiments with disaggregated cells without cAMP, the first samples were isolated $30 \mathrm{~min}$ after removal of the label. The latter sampling protocol was chosen because preliminary experiments indicated that, in disaggregated cells without CAMP, significant amounts of labeled poly $(\mathrm{A})^{+}$RNA decayed during the first hour after cell disaggregation (see below). In each experiment, the time at which the first sample was withdrawn was designated $t_{0}$. During each chase, no increase in the specific activity of rRNA was observed (data not shown), suggesting that reasonably effective chases were obtained.

(i) mRNA population decay rates. Figures $1 \mathrm{~A}$ and $\mathrm{B}$ show the decay of total cytoplasmic poly $(A)^{+}$RNA in cells disaggregated in the presence and absence of cAMP, respectively. In the presence of cAMP, pulse-labeled poly $(A)^{+}$ RNA decayed, after a short lag, with a half-life of $3.8 \mathrm{~h}$. In the absence of cAMP, no lag was observed in poly $(\mathrm{A})^{+} \mathrm{RNA}^{+}$ decay; under these conditions, the kinetics of RNA decay appeared to be biphasic. Over $60 \%$ of the poly $(A)^{+}$RNA in cells disaggregated without cAMP decayed with a half-life of $30 \mathrm{~min}$, and the remainder decayed with a half-life of $4.3 \mathrm{~h}$. The rapid degradation of a substantial fraction of the mRNA population in cells disaggregated in the absence of cAMP is consistent with the results of Mangiarotti et al. $(21,22)$, Chisolm et al. (7), and Chung et al. (8). It is likely that these rapidly degraded RNA species are exclusively cell-typespecific mRNAs, i.e., prestalk and prespore mRNAs (1, 7, 27). Since most developmentally regulated mRNAs are cell type specific (1), the results shown in Fig. 1B suggest that developmentally regulated mRNAs represent as much as 60 to $70 \%$ of the poly $(\mathrm{A})^{+}$RNAs labeled in our pulse-chase experiments. Because developmentally regulated mRNAs normally constitute only 30 to $35 \%$ of the mass of cytoplasmic poly $(\mathrm{A})^{+}$RNA in developing aggregates $(3,8)$, the overrepresentation of these species in our labeled RNA must be a consequence of their high levels of transcription (15). The slowly decaying component shown in Fig. 1B must consist of residual cell-type-specific mRNAs, developmentally regulated common mRNAs (i.e., mRNAs common to both prestalk and prespore cells), and constitutive mRNAs. Since the common mRNAs do not appear to be very abundant (1), most of the RNAs in this slowly decaying component must be constitutive mRNAs. The results of Fig. $1 \mathrm{~B}$, therefore, appear to be consistent with the idea that most, if not all, constitutive mRNAs in late-developing Dictyostelium cells turn over with half-lives of approximately $4 \mathrm{~h}(7,8,18,21,22)$. In spite of the consistency of these data with previously published work, the results presented below suggest that the amount of reliable information that can be drawn from an RNA population decay curve about the turnover kinetics of the population members may be quite limited.

The lag observed in the decay of cytoplasmic poly $(\mathrm{A})^{+}$ RNA in cells disaggregated with cAMP may indicate that the $\mathrm{PO}_{4}$ pools in these cells equilibrate slowly after a chase is initiated (i.e., high-level ${ }^{32} \mathrm{PO}_{4}$ incorporation continues for some time after label removal), or it may reflect the extended mRNA precursor processing and transport times reported for developing cells (23), or both. The failure to detect such a lag in cytoplasmic poly $(\mathrm{A})^{+}$RNA decay in disaggregated cells without cAMP is not surprising since, as noted above, most of the mRNAs labeled in these experiments require cAMP to be synthesized and are rapidly degraded in its absence.

(ii) Decay rates of individual mRNAs. Figure 2 shows a comparison of the decay kinetics of 10 different pulselabeled mRNAs in cells disaggregated with or without cAMP. The decay curves shown in Fig. 2 were generated from an analysis of cDNA dot hybridizations with the same labeled poly $(\mathrm{A})^{+}$RNAs used for the experiments of Fig. 1A and $B$. The mRNAs studied here include one constitutive species (CON29), one common species (COM10C3), five prespore species (PSP7E3, PSP12H5, PSP15E3, PSP2H3, PSP14E6), and three prestalk species (PSK2H6, PSK16G1, PSK18G1). Estimated decay rates derived from the curves presented in Fig. 2 are shown in Table 1.

All but two mRNAs (CON29, PSP7E3) in disaggregated cells with cAMP decayed during the chase period (Fig. 2, Table 1). Of the remaining eight mRNAs, four decayed with first-order kinetics (COM10C3, PSP12H5, PSP15E3, PSK2H6), and four seemed to decay with biphasic kinetics (PSP2H3, PSP14E6, PSK16G1, PSK18G1). The significance 

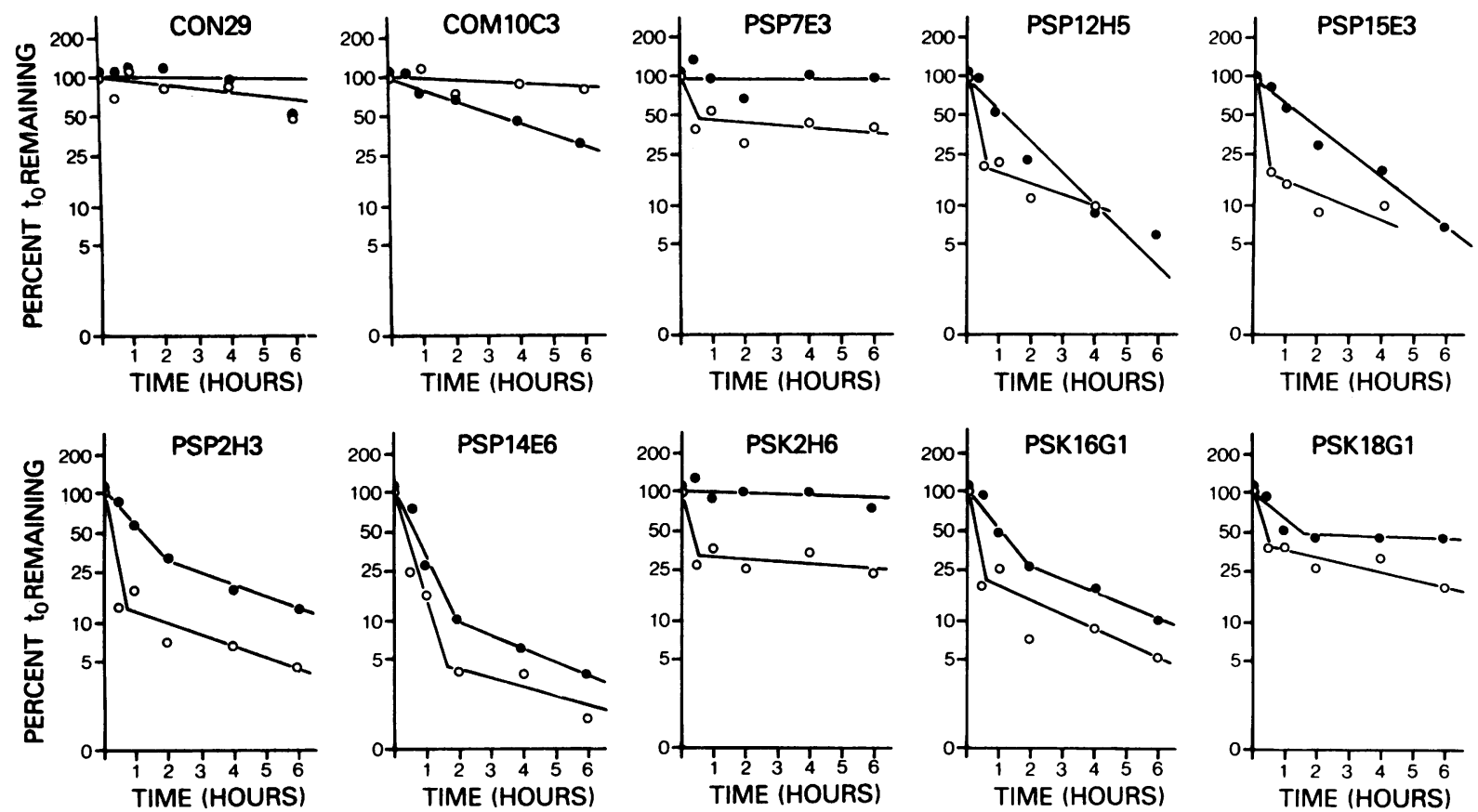

FIG. 2. Decay of specific mRNAs during chases in cells disaggregated in the presence or absence of cAMP. Developing cells were pulse-labeled as described in the legend to Fig. 1, and the incorporated label was chased in disaggregated cells with cAMP (O) or without cAMP (O). Cytoplasmic poly(A) ${ }^{+}$RNA was isolated from cell samples harvested at designated times during the chases, and identical amounts of RNA from each time point in a chase were hybridized to DNA dots containing excess amounts of recombinant cDNA plasmids bearing inserts complementary to specific mRNAs. The extent of hybridization to each dot was quantitated by densitometry of autoradiograms, and changes in the amounts of labeled hybridizable RNA remaining as a function of time were calculated.

of the biphasic decay of some of these mRNAs is unclear. All of the mRNAs are encoded by single-copy genes (27), and only one hybridizing species was detected for each mRNA when Northern blots were probed with labeled complementary DNA (27; data not shown; see Fig. 5). All of the mRNAs that we have examined in growing cells, including precociously expressed PSK18G1 mRNA, decay with first-order kinetics (33); however, the biphasic decay of at least one developmentally regulated mRNA during spore germination has been reported (14). Surprisingly, only one mRNA (COM10C3) in disaggregated cells (with cAMP) decayed at a rate similar to that of the $\operatorname{poly}(A)^{+}$RNA population (Table 1). Most of the other mRNAs decayed two to three times faster than the population rate, or at least some portion of the hybridizable mRNA decayed at a significantly faster rate. Pulse-labeled PSK2H6 mRNA decayed with a half-life that was five times longer than that of the $\operatorname{poly}(\mathrm{A})^{+}$RNA population. These results have been reproduced in several independent experiments (data not shown) and differ markedly from those of Mangiarotti et al. $(21,22)$ and Chisolm et al. (7). This difference can be explained by assuming that we obtained much more effective $\mathrm{PO}_{4}$ chases in our experiments. Thus, it appears that mRNA decay rates in developing cells disaggregated in the presence

TABLE 1. mRNA decay in late-developing cells

\begin{tabular}{|c|c|c|c|c|c|c|c|}
\hline \multirow{3}{*}{ RNA } & \multicolumn{5}{|c|}{ Half-life (h) in pulse-chase experiments } & \multirow{2}{*}{\multicolumn{2}{|c|}{$\begin{array}{c}\text { Half-life (h) of mRNA } \\
\text { loss rates } \\
\text { (disaggregated, without cAMP) }\end{array}$}} \\
\hline & \multicolumn{2}{|c|}{$\begin{array}{l}\text { Disaggregated } \\
\text { (with cAMP) }\end{array}$} & \multicolumn{2}{|c|}{$\begin{array}{c}\text { Disaggregated } \\
\text { (without cAMP) }\end{array}$} & \multirow{2}{*}{$\begin{array}{l}\text { Intact aggregates } \\
\text { (first order) }\end{array}$} & & \\
\hline & First order & $\begin{array}{c}\text { Complex } \\
\text { (fast, slow) }\end{array}$ & First order & $\begin{array}{c}\text { Complex } \\
\text { (fast, slow) }\end{array}$ & & First order & $\begin{array}{c}\text { Complex } \\
\text { (fast, slow) }\end{array}$ \\
\hline 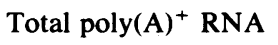 & 3.8 & & & $0.4,4.3$ & 3.8 & & \\
\hline \multicolumn{8}{|c|}{ Specific mRNA (cDNA clone) } \\
\hline CON29 & No decay & & 11.0 & & 3.8 & & \\
\hline COM10C3 & 3.4 & & 21.0 & & 14.0 & 4.0 & \\
\hline PSP7E3 & No decay & & & $0.5,12.0$ & No decay & & \\
\hline PSP12H5 & 1.2 & & & $0.3,3.5$ & No decay & & $0.6,2.0$ \\
\hline PSP15E3 & 1.5 & & & $0.2,3.0$ & No decay & & $0.7,3.0$ \\
\hline PSP2H 3 & & $1.2,3.3$ & & $0.3,3.5$ & No decay & & \\
\hline PSP14E6 & & $0.7,3.6$ & & $0.4,2.6$ & No decay & & \\
\hline PSK2H6 & 20.0 & & & $0.3,15.0$ & 2.8 & & 1.0 , no decay \\
\hline PSK16G1 & & $1.1,3.3$ & & $0.3,2.7$ & 3.2 & & \\
\hline PSK18G1 & & $1.6,23.0$ & & $0.5,5.0$ & No decay & & $0.9,8.0$ \\
\hline
\end{tabular}



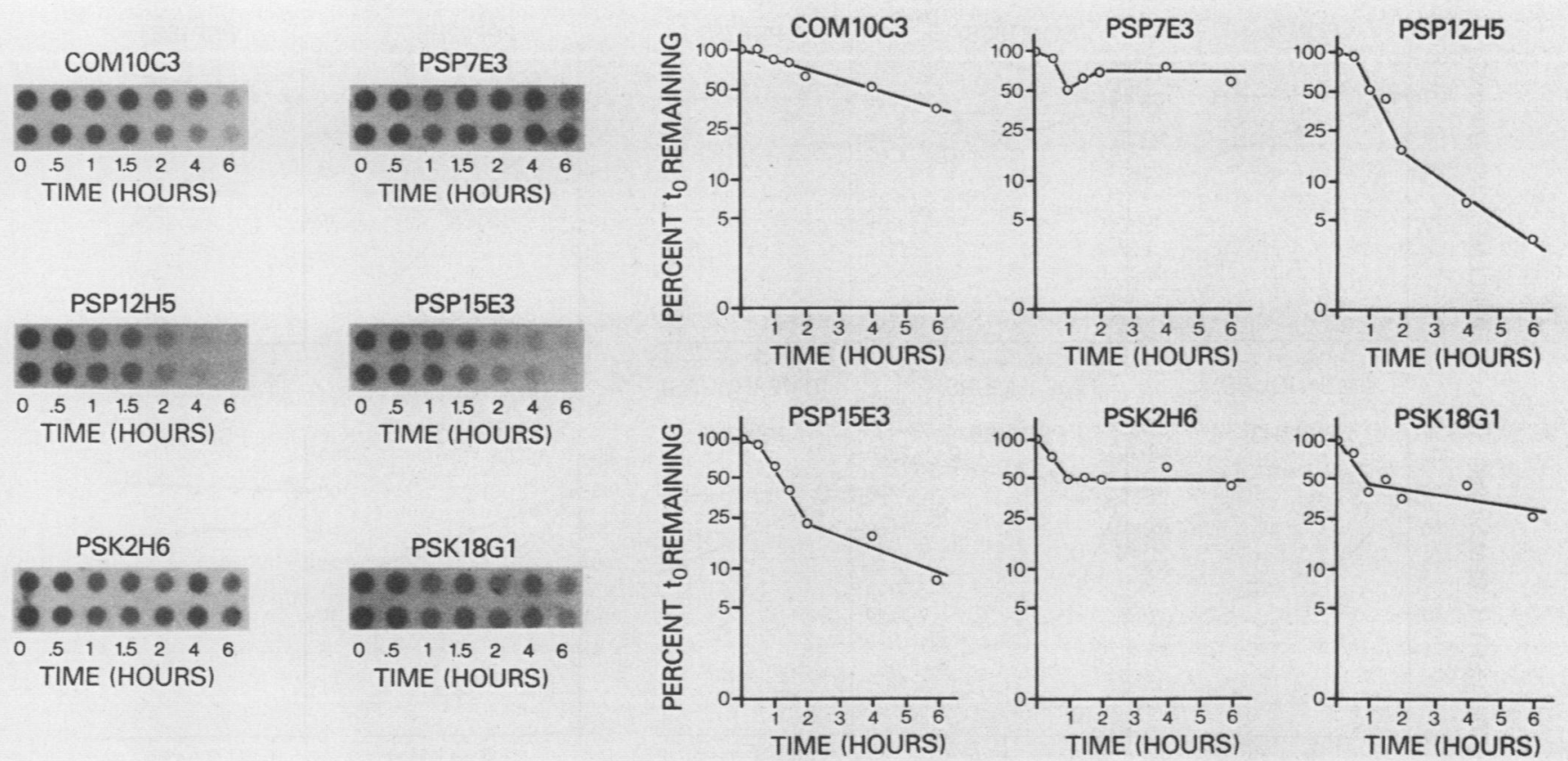

FIG. 3. Specific mRNA levels in cells disaggregated in the absence of cAMP. Total cytoplasmic RNA was isolated from the cells of intact aggregates $\left(15 \mathrm{~h}\right.$ of development; $\left.t_{0}\right)$ and from cells disaggregated for designated lengths of time in the absence of cAMP. Sets of duplicate RNA dots were prepared with 3.0- $\mu \mathrm{g}$ samples of the isolated RNAs, and the relative amounts of specific mRNAs present in each sample were determined by hybridization with ${ }^{32} \mathrm{P}$-labeled probes and densitometry of the resulting autoradiograms. Shown are the autoradiograms used to quantitate the relative amounts of RNA present and semilogarithmic plots of the relative RNA levels as a function of time.

of cAMP are much more heterogeneous than previously thought.

Surprisingly, all of the pulse-labeled prestalk and prespore mRNAs in cells disaggregated without cAMP exhibited biphasic decay kinetics (Fig. 2). This was observed even for those cell-type-specific mRNAs not requiring cAMP to persist in disaggregated cells (e.g., PSK18G1, PSP7E3, and, in our hands, PSK2H6 [27]). During the first 1 to $1.5 \mathrm{~h}$ after disaggregation, all of the prestalk and prespore mRNAs that we studied decayed with half-lives of 20 to $30 \mathrm{~min}$. After this period of rapid decay, significant amounts of each mRNA remained, and the residual molecules decayed with half-lives that were, in most cases, either the same as or longer than those measured in the presence of cAMP (i.e., PSP12H5, PSP15E3, PSP2H3, PSK2H6, PSK16G1; Table 1). Although the decay rates exhibited by the common mRNA (COM10C3) and the constitutive mRNA (CON29) in disaggregated cells without cAMP were different from those measured in the presence of cAMP (Fig. 2, Table 1), these mRNAs decayed with first-order kinetics in both situations, and their decay rates were not markedly accelerated during the first 1 to $1.5 \mathrm{~h}$ after disaggregation. It appears, therefore, that only cell-type-specific mRNAs are subject to a period of rapid and selective degradation in cells disaggregated in the absence of cAMP. Moreover, those prestalk and prespore mRNAs that require cAMP for their maintenance in disaggregated cells were degraded to a greater extent during this initial period of rapid mRNA decay than were those mRNAs that do not (Fig. 2; compare PSP12H5, PSP15E3, PSP2H3, PSP15E6, and PSK16G1 with PSP7E3, PSK2H6, and PSK18G1). Thus, the decay of cell-type-specific mRNAs in cells disaggregated without cAMP also seems to be much more complex than previously recognized.

It is significant that after 1 to $1.5 \mathrm{~h}$ of disaggregation in the absence of cAMP, most prestalk and prespore mRNAs decayed at rates that were the same as or longer than those measured in the presence of cAMP. This observation establishes that cAMP cannot act directly to stabilize cell-typespecific mRNAs in developing cells.

Relative amounts of individual mRNAs in cells disaggregated in the absence of cAMP. Additional evidence that the decay of cell-type-specific mRNAs in disaggregated cells without cAMP is very complex was obtained by using a different approach. Duplicate RNA dots containing fixed amounts of total cytoplasmic RNA isolated from the cells of intact aggregates or cells disaggregated for designated periods of time in the absence of cAMP were prepared and probed to determine changes in the relative levels of six of the developmentally regulated mRNAs studied here. As before, relative mRNA levels were quantitated by densitometric analysis of autoradiograms (Fig. 3). The set of mRNAs analyzed included the common mRNA (COM10C3) as a control and two mRNAs (PSP12H5, PSP15E3) that have consistently exhibited a requirement for cAMP to be maintained at significant levels in disaggregated cells (data not shown). The three other mRNAs (PSP7E3, PSK2H6, PSK18G1) could be readily detected in disaggregated cells without cAMP even after prolonged incubation periods (data not shown; see below). As expected, the levels of all cell-type-specific mRNAs analyzed were sharply reduced during a relatively short period of time after disaggregation in the absence of cAMP (Fig. 3). Interestingly, the loss of the prestalk mRNAs (PSK2H6, PSK18G1) began immediately upon disaggregation, but all of the prespore mRNAs (PSP7E3, PSP12H5, PSP15E3) exhibited a short lag before the onset of mRNA loss. At the end of this period of rapid degradation, the mRNA complementary to the prespore clone PSP7E3 began to reaccumulate, reaching a level 75 to $80 \%$ of that observed in the cells of intact aggregates. A similar reaccumulation was expected for the mRNAs com- 

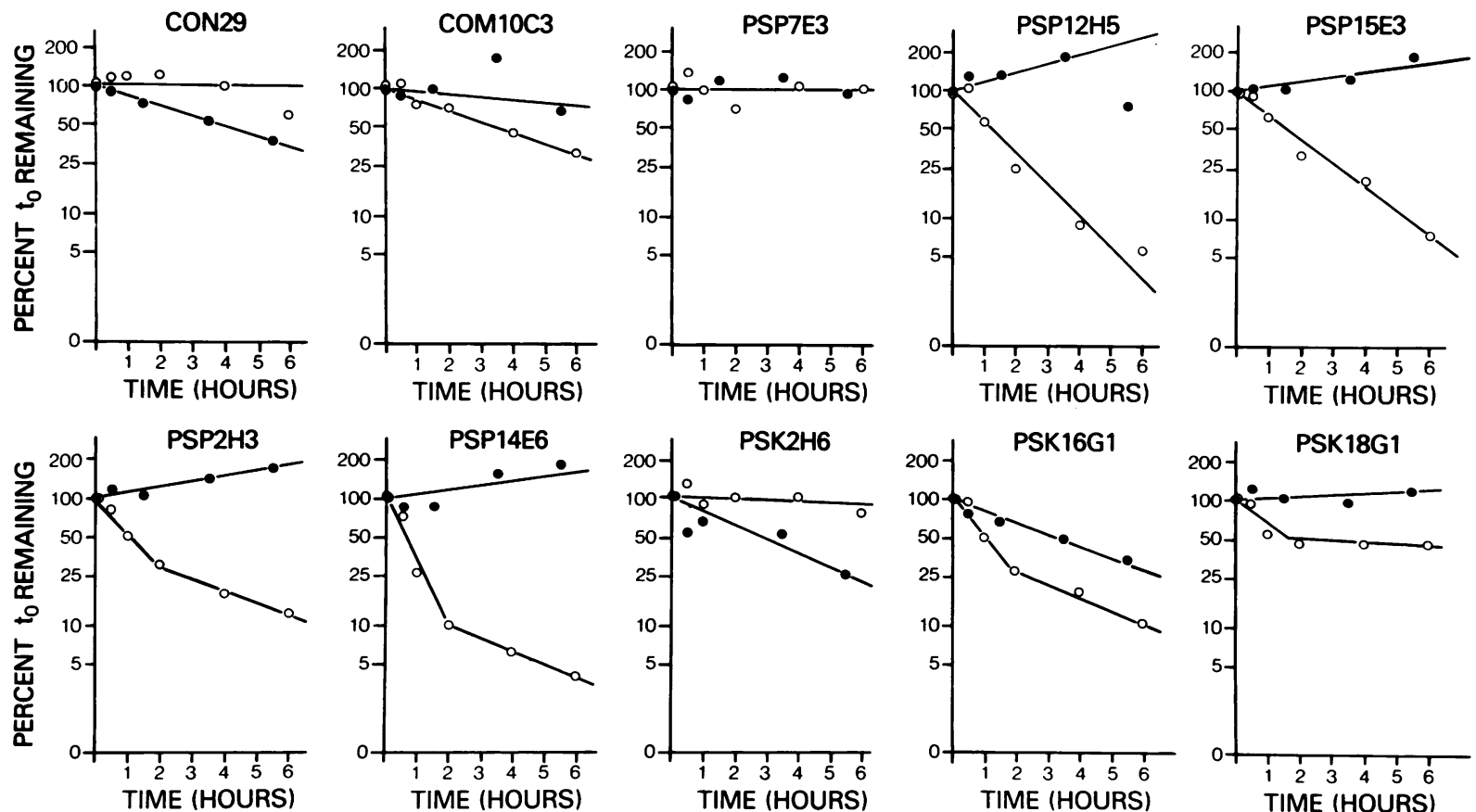

FIG. 4. Décay of specific mRNAs during chases in aggregated cells or cells disaggregated in the presence of cAMP. Developing cells were pulse-labeled as described in the legend to Fig. 1, and the incorporated label was chased in aggregated cells (O) as described in the Materials and Methods. The amounts of specific labeled RNAs remaining as a function of time were measured as described for Fig. 2. The data for mRNA decay in disaggregated cells with cAMP $(O)$ are reproduced from Fig. 2.

plementary to the clones PSK18G1 and PSK2H6, but this was not observed. Since the mRNAs complementary to the clones PSP12H5 and PSP15E3 exhibit an absolute requirement for cAMP to be maintained in disaggregated cells, we expected that the kinetics of their loss in such cells would parallel the decay kinetics observed in a pulse-chase experiment. The loss of these mRNAs in disaggregated cellscAMP was indeed biphasic (Fig. 3), but the measured decay rates for the two components were somewhat different than those observed in a pulse-chase experiment (Table 1). In particular, the decay rates measured for the period of rapid mRNA loss were two to three times slower than those observed in pulse-chase experiments. It is possible that reducing the cAMP-dependent transcription of the genes encoding these mRNAs in disaggregated cells without cAMP is a gradual process and that continued mRNA synthesis contributes to a slower measured decay rate. Nonetheless, the data of Fig. 3 support the idea that cell-type-specific mRNA decay in cells disaggregated without cAMP is extremely complex.

mRNA decay measurements in intact aggregates. To some extent, conclusions about the developmental regulation of mRNA stability in late-developing cells are dependent on the measurement of normal mRNA decay rates. Previous attempts to measure normal mRNA decay rates in late developing cells with ${ }^{32} \mathrm{PO}_{4}$ pulse-chases were done in disaggregated cells with cAMP $(7,21)$. However, gene expression patterns in aggregated cells and cells disaggregated in the presence of CAMP are not entirely the same. Many developmentally regulated mRNAs accumulate to different levels in the two types of cells $(1,16,27)$, and several growthassociated gene products that are either absent or present in greatly reduced amounts in developing cells are reinduced upon cell disaggregation (10). The reaccumulation of these growth-associated gene products upon disaggregation ap- pears to result from the disruption of cell-cell contacts and is largely unaffected by the presence of CAMP (10). In addition, the earlier studies did not apparently consider the possibility that the act of disaggregation itself might result in changes in mRNA decay rates. Therefore, we tried to establish conditions that would yield effective $\mathrm{PO}_{4}$ chases in aggregated cells.

The results of an experiment employing the most effective chase conditions (see Materials and Methods) that we could obtain with intact aggregates are shown in Fig. 1C, Fig. 4, and Table 1 . In this experiment, total labeled cytoplasmic RNA decayed with a half-life of $13 \mathrm{~h}$ (data not shown). Since most of the labeled cytoplasmic RNA in such an experiment is rRNA (data not shown), and since rRNA in late-developing cells turns over with a half-life of approximately $12 \mathrm{~h}$ $(2,20)$, it might be concluded that a reasonably effective chase was obtained. Examination of labeled cytoplasmic poly $(\mathrm{A})^{+}$RNA decay in this experiment (Fig. 1C) is consistent with such a conclusion. As we observed in experiments with cells disaggregated in the presence of cAMP (Fig. 1A), the cytoplasmic poly $(\mathrm{A})^{+}$RNA decayed, after a short lag, with a half-life of $3.8 \mathrm{~h}$ (Table 1 ), suggesting that an equally effective chase had been obtained.

A comparison of the decay rates of labeled individual mRNAs in aggregated cells and disaggregated cells with cAMP revealed, however, that the effectiveness of the chases obtained in the two types of cells were extremely different (Fig. 4). Only four (CON29, COM10C3, PSK2H6, PSK16G1) of the 10 mRNAs studied showed a decrease in specific activity when the chase was performed with intact aggregates (Fig. 4); the other mRNAs either did not decay (PSP7E3) or exhibited increasing specific activities during the chase period (PSP12H5, PSP15E3, PSP2H3, PSP14E6, PSK17G1). In disaggregated cells with CAMP (Fig. 4), 8 of 10 mRNAs decayed during the chase. Clearly, a much more 
PSK $2 \mathrm{H} 6$

CON29

a b c d e

FIG. 5. Northern blot analysis of the PSK2H6 and CON29 mRNAs. Samples $(5 \mu \mathrm{g})$ of total cytoplasmic RNA from growing cells, normal developing cells, and cells that were disaggregated in the presence or absence of cAMP were subjected to electrophoresis in a $1.2 \%$ agarose gel containing $2.2 \mathrm{M}$ formaldehyde. After electrophoresis, the RNAs were blotted to a Zeta-Probe membrane and hybridized with a ${ }^{32}$ P-labeled probe complementary to the PSK2H6 mRNA. After hybridization, the membrane was washed and placed under X-ray film at $-70^{\circ} \mathrm{C}$ with an intensifying screen. The film exposure time was $15 \mathrm{~h}$. The membrane was subsequently reprobed, without stripping, with ${ }^{32} \mathrm{P}$-labeled DNA complementary to the CON29 mRNA. The membrane was then washed and placed under $\mathrm{X}$-ray film as before for $\mathbf{8 h}$. Lanes: a, RNA from growing cells; $b$, RNA from 15-h developing cells; c, RNA from 19-h developing cells; d, RNA from cells that were allowed to develop for $15 \mathrm{~h}$ and then disaggregated and maintained as single cells in the absence of cAMP for an additional $4 \mathrm{~h}$; e, RNA from cells that were allowed to develop for $15 \mathrm{~h}$ and then disaggregated and maintained as single cells in the presence of cAMP $(100 \mu \mathrm{M})$ for an additional $4 \mathrm{~h}$.

effective chase was obtained in the disaggregated cells. An increase in mRNA specific activity under chase conditions can only be explained by efficient incorporation of residual ${ }^{32} \mathrm{PO}_{4}$ into newly synthesized RNA molecules. Incorporation of residual labeled $\mathrm{PO}_{4}$ is more likely to be a problem with developmentally regulated mRNAs than with constitutive mRNAs, since Landfear et al. (15) have shown that developmentally regulated genes are transcribed at rates that are 4 to 10 times higher than those observed for constitutive genes. The chase obtained in disaggregated cells with cAMP was not entirely effective, however, since mRNAs complementary to the CON29 and PSK2H6 cDNA clones exhibited longer half-lives in these cells than they did in aggregated cells. It is likely that this slower decay in disaggregated cells is a consequence of continued ${ }^{32} \mathrm{PO}_{4}$ incorporation. Barklis and Lodish (1) have shown that some developmentally regulated mRNAs accumulate to higher levels in disaggregated cells with cAMP, and, as noted above, some constitutive mRNAs are transcribed at higher rates when cell-cell contacts are disrupted (10). Northern blot analysis of the relative amounts of CON29 and PSK2H6 complementary mRNAs in growing, intact developing, and disaggregated cells is consistent with this interpretation (Fig. 5). Disaggregated cells (with or without cAMP) contained 1.5 times as much CON29 complementary RNA as did the cells of intact aggregates (Fig. 5, compare lanes $b$ and $c$ with lanes $d$ and $e$ ). Similarly, disaggregated cells (with cAMP) contained 3.2 times as much PSK2H6 complementary RNA as did aggregated cells (Fig. 5, compare lanes b and c with lane e).

Most of the individual mRNA decay rates measured in the cells of intact aggregates differed significantly from the rate measured for the poly(A) ${ }^{+}$RNA population to which they belong (compare Fig. 1C with Fig. 4; Table 1). A similar statement can also be made about the mRNA decay rates measured in disaggregated cells with cAMP (compare Fig. 1A and Fig. 2; Table 1). An mRNA population decay curve describes the average amount of mRNA turned over as a function of time in a given mRNA population. Our data indicate that examination of such a curve, with regard to identifying the true diversity of the decay rates of the component mRNAs, may not be very informative.

\section{DISCUSSION}

We have attempted to answer the following questions concerning mRNA metabolism in late-developing $D$. discoideum cells. (i) Can effective $\mathrm{PO}_{4}$ chases be obtained? (ii) Are the decay rates of individual mRNAs uniform or heterogeneous? (iii) Can reliable information about the decay rates of individual mRNAs be deduced from the decay kinetics of total mRNA? (iv) What effect does disaggregation have on the decay rates of cell-type-specific mRNAs? (v) Does cAMP stabilize cell-type-specific mRNAs in disaggregated cells?

A reevaluation of the use of ${ }^{32} \mathrm{PO}_{4}$ pulse-chases to analyze mRNA decay rates seemed necessary since earlier claims (7, $21,22)$ that entirely effective $\mathrm{PO}_{4}$ chases could be obtained in disaggregated developing cells appeared to be inconsistent with observations that we made in ${ }^{32} \mathrm{PO}_{4}$ pulse-chase experiments with growing cells (33). We find that completely effective $\mathrm{PO}_{4}$ chases are difficult, if not impossible, to obtain in growing cells (33). Using our best chase conditions, growth-phase mRNAs labeled in ${ }^{32} \mathrm{PO}_{4}$ pulse decay at rates that are 1.5 to 2 times longer than expected (33). Using very similar chase conditions, Mangiarotti et al. (21) and Chisolm et al. (7) reported that effective $\mathrm{PO}_{4}$ chases could be obtained in late-developing cells disaggregated in the presence of cAMP and concluded that all mRNAs in such cells turn over with half-lives of $4 \mathrm{~h}$. We have also used ${ }^{32} \mathrm{PO}_{4}$ pulse-chases to analyze mRNA decay rates in disaggregated cells with cAMP. In our experiments, total cytoplasmic poly $(A)^{+}$RNA also appeared to decay with a half-life of approximately $4 \mathrm{~h}$. However, our results indicate that individual mRNA decay rates in late-developing cells are much more heterogeneous than the population decay data would suggest. Only 1 of 10 mRNAs studied appeared to turn over at a rate similar to that of the poly $(\mathrm{A})^{+}$RNA population. Two other mRNAs decayed at rates that were two to three times faster than that measured for the poly $(\mathrm{A})^{+}$RNA population, three species decayed at rates that were at least five times slower than the population rate, and the remaining four mRNAs exhibited biphasic decay kinetics. At least some portion of each mRNA that exhibited biphasic decay kinetics decayed at a rate that was two to four times faster than that measured for the $\operatorname{poly}(\mathrm{A})^{+}$RNA population. Since Mangiarotti et al. (21) and Chisolm et al. (7) also studied a large number of individual mRNAs, we conclude that our faster measured mRNA decay rates indicate that we obtained more effective $\mathrm{PO}_{4}$ chases than they did.

Because we were concerned that disaggregation itself might somehow affect mRNA turnover rates in late-developing cells, we also tried to establish conditions that would allow ${ }^{32} \mathrm{PO}_{4}$ pulse-chase experiments to be done with aggregated cells (i.e., normal developing cells). Since most developmentally regulated mRNAs continue to be accumulated in disaggregated cells with cAMP $(1,6,8,15,16,21,22,27)$, Mangiarotti et al. (21) apparently assumed that these cells and aggregated cells were equivalent. However, several observations indicate that gene expression patterns in these two types of cells, although very similar, are not identical (1, $10,16,27$ ) (see above). Unfortunately, the best $\mathrm{PO}_{4}$ chases that we could obtain with aggregated cells were not as effective as those obtained for disaggregated cells with cAMP. In these less effective chases, residual ${ }^{32} \mathrm{PO}_{4}$ was incorporated into most of the mRNAs studied to such an 
extent that they did not appear to decay during the chase periods. However, two of the mRNAs studied did exhibit faster decay rates in aggregated cells than they did in disaggregated cells with cAMP. The simplest explanation for this observation is that even the chases obtained in disaggregated cells with cAMP were not completely effective. Many gene products, including those that are constitutively expressed or developmentally regulated, are accumulated at higher levels in disaggregated cells than they are in the cells of intact aggregates $(1,10)$ (see above). If this greater accumulation is the result of increased transcription, it is possible that mRNA half-lives would appear longer in the presence of residual ${ }^{32} \mathrm{PO}_{4}$ due to increased incorporation of that label into newly synthesized mRNA molecules. Northern blotting experiments indicate that the two mRNAs exhibiting longer half-lives in disaggregated cells with cAMP are both accumulated to higher levels upon the disruption of cell-cell contacts. This increased accumulation for one of the mRNAs (developmentally regulated PSK2H6) was dependent upon the presence of cAMP; the increased accumulation of the other mRNA (constitutive CON29) was insensitive to the presence or absence of cAMP.

It is noteworthy that the poly(A) ${ }^{+}$RNA populations in aggregated cells and disaggregated cells with cAMP decayed at the same rate in our ${ }^{32} \mathrm{PO}_{4}$ pulse-chase experiments, in spite of the obvious difference in chase effectiveness obtained with the two types of cells. In addition, no label was incorporated into stable RNAs (i.e., rRNAs) during the chase portions of any of our experiments. Since the failure to incorporate residual label into rRNA during the chase part of a pulse-chase experiment is frequently used to argue that the chase in question was effective, our results indicate that such a standard may be inadequate. Since most of the mRNAs that we studied are developmentally regulated and since developmentally regulated mRNAs appear to be transcribed at much higher rates than constitutive mRNAs in developing $D$. discoideum cells (15), the problem of incorporation of residual label into newly synthesized mRNA molecules may have been especially acute in our experiments. Conceivably, though, this problem might be encountered in other systems when pulse-chase experiments are used to analyze the decay rates of developmentally regulated mRNAs.

Mangiarotti et al. $(21,22)$ and Chisolm et al. (7) also used ${ }^{32} \mathrm{PO}_{4}$ pulse-chases to study mRNA decay in developing cells disaggregated in the absence of cAMP. They concluded that most of the mRNAs that are preferentially accumulated in either prestalk or prespore cells are selectively degraded in the absence of cAMP, decaying with first-order kinetics and half-lives of 20 to $30 \mathrm{~min}$; the stability of the developmentally regulated, cell-type nonspecific mRNAs (i.e., the common mRNAs) and the constitutive mRNAs seemed to be unaffected by the absence of $\operatorname{cAMP}(7,21,22)$. Based on their results and those of Chung et al. (8), Mangiarotti et al. (21) and Chisolm et al. (7) proposed that cAMP acts to stabilize cell-type-specific mRNAs in normal developing cells. We have also investigated the decay of pulse-labeled mRNAs in disaggregated cells without cAMP. However, we monitored our chases for up to $6 \mathrm{~h}$, instead of the $90-\mathrm{min}$ chase periods monitored by Mangiarotti et al. $(21,22)$ and Chisolm et al. (7). The use of longer chase periods allowed us to determine that the decay kinetics of cell-type-specific mRNAs in disaggregated cells without cAMP are much more complex than previously recognized. In partial agreement with the observations of Mangiarotti et al. $(21,22)$ and Chisolm et al. (7), we found that all of the cell-type-specific mRNAs that we studied were selectively degraded during the first 1 to $1.5 \mathrm{~h}$ after cell-cell disaggregation in the absence of cAMP (half-life of 20 to $30 \mathrm{~min}$ ). However, this period of selective degradation was only transient. At its end, significant amounts of each cell-type-specific mRNA remained, and the residual mRNAs decayed with half-lives that were, on average, the same as those measured in the presence of cAMP. The selective degradation of cell-type-specific mRNAs in disaggregated cells without cAMP was observed even for those species not requiring cAMP for their maintainance in disaggregated cells. (It should be noted that two of the developmentally regulated mRNAs studied by Mangiarotti et al., clones GM27 and GM19 [22], also appeared to exhibit such biphasic decay kinetics even during the limited time courses used.) We conclude from these observations that cAMP does not act directly to stabilize prestalk and prespore mRNAs in developing Dictyostelium cells. However, lowering cAMP levels below some threshold concentration may somehow induce the transient and selective degradation of these mRNAs. Analysis of relative mRNA levels in aggregated and disaggregated cells without cAMP as a function of time reveals additional complexity in the decay of cell-type-specific mRNAs in the absence of cAMP. For example, the selective degradation of prestalk mRNAs appears to begin immediately upon cellular disaggregation, whereas the rapid decay of the prespore mRNAs is delayed for about $30 \mathrm{~min}$. Collectively, these data indicate that mRNA decay kinetics in late-developing $D$. discoideum cells are much more complex than previously thought.

Our experiments also provide some insight into the significance of the observation that many developmentally regulated mRNAs require cAMP for their maintenance in disaggregated cells (as monitored by their detectability on Northern blots). Our data suggest that those mRNAs whose relative abundance decreases most dramatically in the absence of cAMP do so as a consequence of two factors: (i) substantial reductions in their rates of transcription (15) and (ii) inherently fast normal rates of decay (i.e., even in the presence of cAMP, these mRNAs have very short halflives).

\section{ACKNOWLEDGMENTS}

R.E.M. thanks Laura F. Steel and David Herrick for teaching him the molecular techniques used in these experiments. We thank Susan Longwell for word processing assistance.

This work was funded by a Public Health Service grant to A.J. from the National Institutes of Health.

\section{LITERATURE CITED}

1. Barklis, E., and H. F. Lodish. 1983. Regulation of Dictyostelium discoideum mRNAs specific for prespore or prestalk cells. Cell 32:1139-1148.

2. Batts-Young, B., H. F. Lodish, and A. Jacobson. 1980. Similarity of the primary sequences of ribosomal RNAs isolated from vegetative and developing cells of Dictyostelium discoideum. Dev. Biol. 78:352-364.

3. Blumberg, D. D., and H. F. Lodish. 1980. Changes in the messenger RNA population during differentiation of Dictyostelium discoideum. Dev. Biol. 78:285-300.

4. Buckingham, M. E., D. Caput, A. Cohen, R. G. Whalen, and F. Gros. 1974. The synthesis and stability of cytoplasmic messenger RNA during myoblast differentiation in culture. Proc. Natl. Acad. Sci. USA 71:1466-1470.

5. Casey, L., C. M. Palatnik, and A. Jacobson. 1983. Messenger RNA half-life in Dictyostelium discoideum. Dev. Biol. 95:239243.

6. Chisolm, R. L., E. Barklis, and H. F. Lodish. 1984. Mechanism of sequential induction of cell-type specific mRNAs in Dictyostelium differentiation. Nature (London) 310:67-69. 
7. Chisolm, R. L., D. Fontana, A. Theibert, H. F. Lodish, and P. Devreotes. 1984. Development of Dictyostelium discoideum: chemotaxis, cell-cell adhesion, and gene expression, p. 219-254. In R. Losick and L. Shapiro (ed.), Microbial development. Cold Spring Harbor Laboratory, Cold Spring Harbor, N.Y.

8. Chung, S., S. M. Landfear, D. D. Blumberg, N. S. Cohen, and H. F. Lodish. 1981. Synthesis and stability of developmentally regulated Dictyostelium mRNAs are affected by cell-cell contact and cAMP. Cell 24:785-797.

9. Feinberg, A. P., and B. Vogelstein. 1984. Addendum to "A technique for radiolabeling DNA restriction endonuclease fragments to high specific activity." Anal. Biochem. 139:266-267.

10. Finney, R., M. Ellis, C. Langtimm, E. Rosen, R. Firtel, and D. R. Soll. 1987. Gene regulation during dedifferentiation in Dictyostelium discoideum. Dev. Biol. 120:561-576.

11. Gomer, R. H., S. Datta, M. Mehdy, A. Crowley, A. Silverstein, W. Nellen, C. Reymond, S. Mann, and R. A. Firtel. 1985. Regulation of cell-type-specific gene expression in Dictyostelium. Cold Spring Harbor Symp. Quant. Biol. 50:801-812.

12. Guyette, W. A., R. J. Matusik, and J. M. Rosen. 1979. Prolactinmediated transcriptional and post-transcriptional control of casein gene expression. Cell 17:1013-1023.

13. Johnson, D. A., J. W. Gautsch, J. R. Sportsman, and J. H. Elder. 1984. Improved technique utilizing nonfat dry milk for analysis of proteins and nucleic acids transferred to nitrocellulose. Gene Anal. Tech. 1:3-8.

14. Kelly, R., L. J. Kelly, and H. L. Ennis. 1985. Dictyostelium discoideum mRNAs developmentally regulated during spore germination have short half-lives. Mol. Cell. Biol. 5:133-139.

15. Landfear, S. M., P. Lefebvre, S. Chung, and H. F. Lodish. 1982. Transcriptional control of gene expression during development of Dictyostelium discoideum. Mol. Cell. Biol. 2:1417-1426.

16. Landfear, S. M., and H. F. Lodish. 1980. A role for cAMP in expression of developmentally regulated genes in Dictyostelium discoideum. Proc. Natl. Acad. Sci. USA 77:1044-1048.

17. Lehrach, H., D. Diamond, J. M. Wozney, and H. Boedtker. 1977. RNA molecular weight determinations by gel electrophoresis under denaturing conditions, a critical reexamination. Biochemistry 16:4743-4751.

18. Lodish, H. F., D. D. Blumberg, R. Chisolm, S. Chung, A. Coloma, S. Landfear, E. Barklis, P. Lefebvre, C. Zucker, and G. Mangiarotti. 1982. Control of gene expression, p. 325-352. In W. Loomis (ed.), The development of Dictyostelium discoideum. Academic Press, Inc., New York.

19. Loomis, W. F. 1975. Dictyostelium discoideum: a developmental system. Academic Press, Inc., New York.

20. Mangiarotti, G., F. Altruda, and H. F. Lodish. 1981. Rates of synthesis and degradation of ribosomal ribonucleic acid during differentiation of Dictyostelium discoideum. Mol. Cell. Biol. 1: $35-42$.

21. Mangiarotti, G., A. Ceccarelli, and H. F. Lodish. 1983. Cyclic
AMP stabilizes a class of developmentally regulated Dictyostelium discoideum mRNAs. Nature (London) 301:616-618.

22. Mangiarotti, G., P. Lefebvre, and H. F. Lodish. 1982. Differences in the stability of developmentally regulated mRNAs in aggregated and disaggregated Dictyostelium discoideum cells. Dev. Biol. 89:82-91.

23. Mangiarotti, G., C. Zucker, R. L. Chisolm, and H. F. Lodish. 1983. Different mRNAs have different nuclear transit times in Dictyostelium discoideum aggregates. Mol. Cell. Biol. 3:15111517.

24. Maniatis, T., E. F. Fritsch, and J. Sambrook. 1982. Molecular cloning: a laboratory manual. Cold Spring Harbor Laboratory, Cold Spring Harbor, N.Y.

25. Margolskee, J. P., and H. F. Lodish. 1980. Half-lives of messenger RNA species during growth and differentiation of Dictyostelium discoideum. Dev. Biol. 74:37-49.

26. Mehdy, M. C., and R. A. Firtel. 1985. A secreted factor and cyclic AMP jointly regulate cell-type-specific gene expression in Dictyostelium discoideum. Mol. Cell. Biol. 5:705-713.

27. Mehdy, M. C., D. Ratner, and R. A. Firtel. 1983. Induction and modulation of cell-type-specific gene expression in Dictyostelium. Cell 32:763-771.

28. Oyama, M., and D. D. Blumberg. 1986. Changes during differentiation in requirements for cAMP for expression of cell-typespecific mRNAs in the cellular slime mold, Dictyostelium discoideum. Dev. Biol. 117:550-556.

29. Palatnik, C. M., R. V. Storti, A. K. Capone, and A. Jacobson. 1980. Messenger RNA stability in Dictyostelium discoideum: does poly(A) have a regulatory role? J. Mol. Biol. 141:99-118.

30. Palatnik, C. M., R. V. Storti, and A. Jacobson. 1979. Fractionation and functional analysis of newly synthesized and decaying messenger RNAs from vegetative cells of Dictyostelium discoideum. J. Mol. Biol. 128:371-395.

31. Palatnik, C. M., R. V. Storti, and A. Jacobson. 1981. Partial purification of a developmentally regulated messenger RNA from Dictyostelium discoideum by thermal elution from poly(U)-Sepharose. J. Mol. Biol. 150:389-398.

32. Palatnik, C. M., C. Wilkins, and A. Jacobson. 1984. Translational control during early Dictyostelium development: possible involvement of poly(A) sequences. Cell 36:1017-1025.

33. Shapiro, R. A., D. Herrick, R. E. Manrow, D. Blinder, and A. Jacobson. 1988. Determinants of mRNA stability in Dictyostelium discoideum amoebae: differences in poly(A) tail length, ribosome loading, and mRNA size cannot account for the heterogeneity of mRNA decay rates. Mol. Cell. Biol. 8:19571969.

34. Steel, L. F., and A. Jacobson. 1987. Translational control of ribosomal protein synthesis during early Dictyostelium discoideum development. Mol. Cell. Biol. 7:965-972.

35. Williams, J. G., A. S. Tsang, and H. Mahbubani. 1980. A change in the rate of transcription of a eukaryotic gene in response to cyclic AMP. Proc. Natl. Acad. Sci. USA 77:7171-7175. 